\title{
Developing the Phonemic Awareness of Students Who Are Hard of Hearing and Have Dyslexia
}

\author{
Mohammed Saleh Alajlan ${ }^{1}$ \\ ${ }^{1}$ Department of Special Education, College of Education, Qassim University, Buraydah, Saudi Arabia \\ Correspondence: Mohammed Saleh Alajlan, Department of Special Education, College of Education, Qassim \\ University, Buraydah, Saudi Arabia.
}

Received: August 12, 2021

Accepted: September 18, 2021

Online Published: November 24, 2021

doi:10.5539/ies.v14n12p72

URL: https://doi.org/10.5539/ies.v14n12p72

\begin{abstract}
The term phonemic awareness refers to the ability to not only recognize that language is composed of distinct sounds but also the ability to manipulate those verbalized components of words. It is an essential element of reading, which also affects writing, since the two skills are complementary. English Language Learners (ELLs) and students with dyslexia struggle with phonemic awareness as do hard-of-hearing students. The combination of these characteristics tends to intensify the problems these students have and the support they require, which in turn necessitates awareness on the part of teachers and other education professionals. In this study, synthetic phonics and stretched segmenting are used to develop the phonemic awareness of a hard-of-hearing ELL student diagnosed with dyslexia. This single case study found both strategies to be effective in supporting the subject student.
\end{abstract}

Keywords: phonemic awareness, reading, deaf and hard of hearing, English language learner students

\section{Literature Review}

Oral language and written language interact to develop and support reading and writing. Language development involves many steps, including: (a) building oral language, (b) making connections between oral language and print, (c) building reading skills, which should be supported by vocabulary acquisition that starts at the beginning of the learning process, and (d) developing and implementing comprehension strategies through the process of listening to oral (or spoken) language. Therefore, it is clear that reading comprehension is affected by listening comprehension, for example, if children can understand the meaning of words that they hear and if they can say what they hear-both of which comprise listening comprehension — reading comprehension will come more easily to them (O'Connor, 2007). Again, this shows how reading comprehension and listening comprehension support each other.

Reading comprehension is predicated upon and affected by oral language and word decoding and reading (Davidson et al., 2018; Lervåg et al., 2018). Simply put, having oral skills facilitates reading. O'Connor (2007) stated that preschoolers with a broad vocabulary tend to encounter fewer difficulties in phonemic awareness and alphabetic principle than their peers with smaller vocabularies, because these young children tend to use their existing vocabulary knowledge to locate similarities between the sounds they hear and the letters that they see in words as they read.

In addition to this function of oral language during the development of reading skills, oral language also has an effect on the development of writing skills. As a result, oral language is considered a prerequisite for writing (O'Connor, 2007). Formulating ideas and discussing them usually occurs first in the oral form and subsequently in the written form. Children who possess large numbers of words in oral language are better able to master writing and to learn more easily and faster than children with less-developed oral language (fewer numbers of words). In a study of 293 preschool children who were administered an assessment battery that examined nonverbal cognition, oral language, emergent reading, and writing, it was found that "children with weaker oral language skills lag behind their peers with stronger oral language skills in terms of their writing-related skills" (Puranik \& Lonigan, 2012, p. 179).

The relationship between oral language and writing skills is confirmed by the typical experience of deaf and hard of hearing $(\mathrm{D} / \mathrm{HH})$ students. Generally speaking, these children tend to struggle with both reading and writing (Schirmir, 2000). For example, while deaf students can carry out the practice of writing, their work tends to include 
grammatical errors and a lack of basic structures (Rose et al., 2004), and more syntactic errors than the work of their hearing peers (van Beijsterveldt \& van Hell, 2010). This is related to their lag in the development of oral language, which greatly relies upon listening. This is especially true with deaf children who "do not have full access to language models from birth" (Kilpatrick \& Wolbers, 2020, p. 559).

Although oral language is acquired naturally by the hearing, the development of written language usually requires instruction, and even then students may still have difficulties in mastering the skills (Ariyanti, 2016). Since the skills are interdependent, it is important that the listening and speaking aspects of oral language and the reading and writing aspects of written language are integrated in the process of teaching. Although each of these four skills develops independently, they are connected to each other and the development of one skill will strongly impact and facilitate the development of the other skills. For example, our development of writing interacts with our development of listening, speaking, and reading skills (Berninger, 2000).

A further example of how these skills are complementary is found in how the verbal and listening skills that comprise oral language and the reading and writing skills that comprise written language interact with one another and affect an individual's academic achievement. The acquisition of these skills and the ability to successfully integrate the two types of language and their related skills begins with the child experiencing oral language by developing listening and speaking skills; subsequently, the child begins to develop written language, based on their existing oral language skills. So, it is important to recognize that oral language skills development is the foundation for the development of the reading and writing skills that comprise written language. However, academic achievement does not rely only on oral language skills.

At times, a child's development of oral language skills will be impacted by an identified disability, such as Asperger's syndrome, and appropriate therapeutic methods can be utilized to support the child. However, if a student has another contributing issue that has not been identified - for example, dyslexia - the therapeutic plan for supporting the child's oral and written language skills development will be less successful or even unsuccessful because the IEP only addresses the speech delay issues caused by their Asperger's and does not incorporate support for the dyslexia. This emphasizes the need to look at the whole child and to integrate both a range of assessments as well as a range of treatment plans to ensure that all of the individual child's needs are met in the support of their oral and written language skills development (Silliman \& Berninger, 2011). It also shows that it is necessary to determine if particular strategies can support not just a number of different disabilities/challenges occurring independently (e.g., dyslexia, Asperger's, ELL, or D/HH) but also can support students with multiple disabilities/challenges in combination (e.g., a single ELL student who is $\mathrm{D} / \mathrm{HH}$ and has a diagnosis of dyslexia).

The relationship between oral language development and reading skills can be seen when we examine the student who is both an ELL and has dyslexia. When Silliman and Berninger (2011) examined such cases, they identified five components of reading that this combination of challenges affects: phonemic awareness, phonics, fluency, vocabulary, and comprehension. In terms of phonemic awareness, children with dyslexia have difficulties such as the inability to isolate and blend sounds in parts of words as well as with decoding and encoding for words. Similarly, some ELLs have a shortage in their phonemic awareness and phonological blending, and their segmentation and auditory word discrimination may be weak even though they "relate directly to literacy" (le Roux et al., 2017, p. 1). Therefore, it is necessary to support students who are both dyslexic and ELLs with effective strategies.

One such method for teaching phonemic awareness is "stretched segmenting," which involves saying a word slowly by producing each sound over about 1 or $2 \mathrm{~s}$ (O'Connor, 2007). In this activity, the steps begin with the teacher first choosing simple, one-syllable words, such as foot, and showing the student how to pronounce each sound through modeling. In this step, as noted, the word is spoken with a pause between each sound of about 1 or $2 \mathrm{~s}$. In this example, the word is stated as: "Fffff-uuuhhh-ttt." Then, the student is invited to also stretch out each sound in the word. Finally, the teacher and student repeat the word many times until the teacher feels that the student knows the word. During this activity, the teacher also uses body language by moving their hand from the right to the left slowly to represent to the student how to move through producing the word.

To develop students' phonics and help them overcome their difficulties in remembering sounds (for decoding words) and in obeying phonics rules while reading texts-that arise out of the inability to distinguish between sounds-teachers may implement "synthetic phonics." This is done by blending "sounds that are represented by individual letters or groups of letters and merging these together sequentially for reading," and also involves segmenting, which refers to "the reverse process of separating a word into its constituent phonemes and representing these as graphemes for spelling (Glazzard \& Stones, 2020, p. 3).

The importance of systematic phonics instruction as it supports the teaching of reading has been recognized by 
organizations and governments in a number of English-speaking countries (e.g., the National Reading Panel in the United States and the Australian government; Wyse \& Goswami, 2008). Putri and Hateem (2020) conducted a true-research experimental study including one group pre-test and post-test to investigate the effect of synthetic phonics on the development of eighth-grade students' reading aloud skills. Students from two classes $(N=72)$ participated; one class was designated experimental and the other was the control. The synthetic phonics strategy involves the following techniques. The teacher introduces the letter to be taught with its sound, this can be done using a picture or song. Next, the teacher explains to the students how to highlight, code, and blend sounds. Then the teacher and students read the letters and apply the strategies of highlighting, coding, and blending sounds. After that, they (i.e., the teacher and students) write the letter through sky writing, segment, and spelling. Finally, students read the letters presented in words in phrases, sentences, and stories.

In this strategy, the teacher instructs the students in how to read and spell at the same time, by enabling them to form sounds from letters and then blending these sounds to form words. For example, the teacher may introduce the three letters of $c a r$, using: $c+a+r=$ "car". Another function of this strategy is segmentation, where students learn to segment sounds to spell, such as "car" $=\mathrm{c}+\mathrm{a}+\mathrm{r}$. This strategy trains students the alphabet code that they can use to read unknown words.

Comparison of the obtained results from the experimental group with that of the control on the pre-test and post-test tests, found significant differences. The researchers found synthetic phonics to be an effective strategy for the development of students' reading aloud skills (Putri \& Hateem, 2020).

However, although these strategies have been found to be effective with students who are ELL and who also have dyslexia, it is necessary to examine the effectiveness of these strategies with the population of ELLs with dyslexia who are also $\mathrm{D} / \mathrm{HH}$. Therefore, we present this study, which was designed to investigate the effectiveness of these activities in developing the phonemic awareness of this hard of hearing student with the stated combination of challenges.

\section{Methodology}

\subsection{Subject}

In the present study, the aforementioned strategies and activities for developing phonemic awareness were introduced to support Al-Munther (a pseudonym), a hard-of-hearing Libyan student in the fourth grade who had been diagnosed with dyslexia. The subject, who lives in the state of Colorado, arrived in the United States having completed first grade in his native Libya. He then attended the second and third grades at a Libyan school in Denver. Due to his being hard of hearing and an English language learner, Al-Munther has had some difficulties with communication.

The subject's fourth grade teacher indicated that because he has a smaller vocabulary than his peers, he has difficulties in reading - particularly in regard to his ability to summarize information. While observing one of his reading classes, the researcher noted that Al-Munther struggled with sounding out and reading new words, as well as with understanding what sounds specific letters represent. Specifically, the subject was unaware of how sounds are coarticulated (i.e., produced with two simultaneous places of articulation). Phoneme substitution of $/ \theta /$ for $/ \delta /$, and $/ \mathrm{i} /$ for $/ \mathrm{I} /$ was also observed in his performance.

\subsection{Procedure}

The first step was to confirm that a possible source of the subject's problem was related to phonemic awareness through observation to establish what will be referred to here as an informal baseline. This was accomplished by asking the student to identify some words as they were pronounced; the subject knew just two out of the seven words. Next, some segmentation exercises were administered, including: first sound isolation, last sound isolation, and complete words. In total, the subject was able to correctly answer about $35 \%$ of the items in the exercises. Al-Munther's low performance with blending and segmentation confirmed that his struggle involved phonemic awareness skills.

At this point, a plan of treatment was designed involving the application of a set of strategies and the intervention was implemented over 2 weeks for 30 min each day during the time of the school day set aside for Al-Munther to receive therapeutic interventions for a total of $5 \mathrm{hr}$ for the entire intervention. Since Al-Munther's phoneme substitution of $/ \theta /$ for $/ \delta /$ and $/ \mathrm{i} /$ for $/ \mathrm{I} /$ was clear, the researcher prepared a lesson on phonemic awareness that focused on phoneme substitution, incorporating certain teaching methods and that included more than one activity. The researcher also modeled the lesson for the student by leading and observing him, and providing corrective feedback as needed. A multi-sensory strategy, where both subject and interventionist touch their mouths and say what they are doing, was also employed. 
Two main activities were incorporated into the lesson: minimal pairs and tongue twisters. These activities were designed to help the subject overcome the issue of phoneme substitution with $/ \theta /$ for $/ \mathrm{d} /$ and $/ \mathrm{i} /$ for $/ \mathrm{I} /$, when reading in English. This is accomplished by encouraging the subject to notice the difference between the two sounds by reading words that have similar sounds but different meanings. Through discriminating phonemes, the subject's ability to read and pronounce words is thereby improved.

Additionally, the lesson was constructed in a way that allowed the teacher (i.e., researcher in this case) to model the lesson in a variety of situations. In the beginning, the researcher gave the student a popsicle stick and told him to use it to sense which part of the mouth is used to produce the target consonant sounds in sets of words, such as the consonant sound after $/ \mathrm{n} /$ in the students' name (Al-Munther), i.e., $/ \mathrm{d} /$; the researcher modeled this activity first and then the student did it on his own.

Then, differences between each of the two sounds were introduced by explaining and modeling how they are produced. Although the researcher had planned on exaggerating his pronunciation to help Al-Munther notice the differences, Al-Munther understood the difference between the sounds and produced them without the need for such exaggeration. The researcher also orally modeled how to pronounce /i/ and /I/. After each modeling activity, the student practiced what he had learned and observed from the researcher's performance.

Another aspect of this strategy involves the teacher providing corrective feedback as needed to the subject, which the researcher employed twice. During the activities for minimal pairs and tongue twisters, the researcher provided a lot of feedback to Al-Munther and also recorded the different issues the student would need to be supported in overcoming in the next lesson. In the independent practice, the teacher's main role is to provide corrective feedback and reinforcement. Although Al-Munther enjoyed reading the tongue twisters with $/ \theta /$ for $/ \mathrm{d} /$ and $/ \mathrm{i} /$ for $/ \mathrm{I} /$, he was not able to pronounce them correctly all the time. Therefore, the researcher observed him while he read and provided corrective feedback when necessary.

This lesson utilizes a "multi-sensory" strategy that incorporates touching and saying what the subject and researcher are doing. Specifically, as the researcher and subject made the different sounds, both were touching their mouths with the popsicle sticks to sense what part of the mouth was moving and involved in producing each sound. This was followed up with having the subject explain the difference between pronouncing each of the two paired sounds to help Al-Munther be aware of each sound as he read.

The researcher relied on the recommendation of O'Connor (2007) regarding the use of two strategies that have been found to increase the effectiveness of teaching phonemic awareness. The first of these is isolating the first phoneme, which in this study involved having Al-Munther say the first sound slowly and then integrating that sound into a complete word. For example, he was directed to say /ðððıs/ when he read this. The second strategy recommended by O'Connor (2007) is isolating the middle phoneme. In this study, the researcher asked the student to read each word in a set of minimal pairs slowly, stopping the student while he was saying the middle sound. Through this method, the researcher documented the effects of the intervention on Al-Munther's phoneme substitution of $/ \theta /$ for $/ \mathrm{d} /$ and $/ \mathrm{i} /$ for $/ \mathrm{I} /$ first, and on his reading, second.

\section{Results}

The effects of integrating the phonemic awareness strategies on phoneme substitution- $/ \theta /$ for $/ \mathrm{d} /$ and $/ \mathrm{i} /$ for $/ \mathrm{I} /$ - were observed by recoding the changes in Al-Munther's performance in the minimal pairs and tongue twisters. In the beginning during the observation, Al-Munther was found to $82 \%$ of the time substitute $/ \theta /$ for $/ \mathrm{d} /$ and $90 \%$ of the time to substitute $/ \mathrm{i} /$ for $/ \mathrm{I} /$. After intensive training on minimal pairs and tongue twisters, with modeling and isolating phonemes using popsicle sticks and providing corrective feedback, noticeable effects were observed. Within 1 week, Al-Munther was able to distinguish between each of the sounds the majority of the time $(\sim 87 \%)$. In his reading of the final text presented in the treatment, Al-Munther was able to overcome his problem $97 \%$ of the time.

\section{Discussion and Conclusion}

This study found that implementing the strategies of synthetic phonics and stretched segmenting to develop phonemic awareness in a hard of hearing ELL student diagnosed with dyslexia was effective. This establishes that these strategies, which have been found to be effective for teaching reading to English language learners and to students diagnosed with dyslexia, may also benefit hard of hearing students with both challenges. Breaking up words and decoding them into the smallest units of sound (i.e., phonemes) and blending phonics by having the teacher first deliver the letter sounds in isolation and then building up to blending the sounds together to achieve the full pronunciation of the words was effective in helping this hard of hearing student make the connection between the letters of written texts and the sounds of spoken language. 


\subsection{Limitations}

Although this lesson was effective and markedly beneficial to the student as reflected in the impact on his reading, the study has some obvious limitations. First of all, this research involved only one subject who is a native Arabic speaker, so it cannot be generalized to the general population of all hard of hearing ELL students with dyslexia or even all hard of hearing ELL students with dyslexia whose native language is Arabic. In addition, the implementation of the intervention occurred over only 2 weeks of school days and involved only a total of $5 \mathrm{hr}$ of implementation of the intervention. Moreover, while the student was observed prior to the implementation to confirm the phonemic substitution issue, very little data was acquired to establish a formal baseline. Finally, no follow-up was conducted to determine if the benefits of the intervention were maintained after the intervention was withdrawn.

\subsection{Future Recommendations}

Due to the limitations of the study, certain recommendations for future research are presented. First, future studies on the use of these two strategies should involve larger groups of subjects overall as well as Arabic native language students and ELL students whose native language is not Arabic. In addition, some improvements to the intervention should be considered. For example, this lesson is designed to develop segmentation, which only works with students of a certain developmental age. Integrating more and different strategies into the same lesson might achieve greater improvement in the reading performance of hard of hearing ELL students who have been diagnosed with dyslexia. Future studies should also include a more defined baseline phase, a longer intervention phase, and an appropriate follow-up phase, to better measure the effectiveness of the intervention for subjects.

\section{References}

Ariyanti, A. (2016). The teaching of EFL writing in Indonesia. Dinamika Ilmu: Jurnal Pendidikan, 16(2), 263-277. https://doi.org/10.21093/di.v16i2.274

Berninger, V. W. (2000). Development of language by hand and its connections with language by ear, mouth, and eye. Topics in Language Disorders, 20(4), 65-84. https://doi.org/10.1097/00011363-200020040-00007

Davidson, M. M., Kaushanskaya, M., \& Weismer, S. E. (2018). Reading comprehension in children with and without ASD: The role of word reading, oral language, and working memory. Journal of Autism and Developmental Disorders, 48(10), 3524-3541. https://doi.org/10.1007/s10803-018-3617-7

Glazzard, J., \& Stones, S. (2020). A rigorous approach to the teaching of reading? Systematic synthetic phonics in initial teacher education [Policy brief]. Frontiers in Education. https://doi.org/10.3389/feduc.2020.587155

Kilpatrick, J. R., \& Wolbers, K. A. (2020). Beyond the red pen: A functional grammar approach to evaluating the written language of deaf students. Psychology in the Schools, 57(3), 459-474. https://doi.org/10.1002/pits.22289

Le Roux, M., Geertsema, S., Jordaan, H., \& Prinsloo, D. (2017). Phonemic awareness of English second language learners. South African Journal of Communication Disorders, 64(1), 1-9. https://doi.org/10.4102/sajcd.v64i1.164

Lervåg, A., Hulme, C., \& Melby-Lervåg, M. (2018). Unpicking the developmental relationship between oral language skills and reading comprehension: It's simple, but complex. Child Development, 89(5), 1821-1838. https://doi.org/10.1111/cdev.12861

O'Connor, R. E. (2007). Teaching word recognition: Effective strategies for students with learning difficulties (1st ed.). Guilford Press.

Puranik, C. S., \& Lonigan, C. J. (2012). Early writing deficits in preschoolers with oral language difficulties. Journal of Learning Disabilities, 45(2), 179-190. https://doi.org/10.1177/0022219411423423

Putri, R. R. N., \& Hateem, Z. (2020). Synthetic phonics on the development of reading aloud. ELLITE: Journal of English Language, Literature, and Teaching, 5(1), 43-49. https://doi.org/10.32528/ellite.v5i1.3309

Rose, S., McAnally, P. L., \& Quigley, S. P. (2004). Language learning practices with deaf children (3rd ed.). Pro-Ed.

Schirmir, B. R. (2000). Language and literacy development in children who are deaf (2nd ed.). Pearson.

Silliman, E. R., \& Berninger, V. W. (2011). Cross-disciplinary dialogue about the nature of oral and written language problems in the context of developmental, academic, and phenotypic profiles. Topics in Language Disorders, 31(1), 6-23. https://doi.org/10.1097/TLD.0b013e31820a0b5b 
Van Beijsterveldt, L. M., \& van Hell, J. (2010). Lexical noun phrases in texts written by deaf children and adults with different proficiency levels in sign language. International Journal of Bilingual Education and Bilingualism, 13(4), 439-468. https://doi.org/10.1080/13670050903477039

Wyse, D., \& Goswami, U. (2008). Synthetic phonics and the teaching of reading. British Educational Research Journal, 34(6), 691-710. https://doi.org/10.1080/01411920802268912

\section{Copyrights}

Copyright for this article is retained by the author(s), with first publication rights granted to the journal.

This is an open-access article distributed under the terms and conditions of the Creative Commons Attribution license (http://creativecommons.org/licenses/by/4.0/). 